\title{
Malaria Incidence and Associated Risk Factors in and Around Anger Gute Town, Western Ethiopia
}

Mebrate Dufera ( $\square$ mebratedufera@gmail.com )

Wollega University

Oljira Kenea

Wollega University

Geleta Tadele

Wollega University

Research

Keywords: Anger Gute, malaria, malaria incidence

Posted Date: May 19th, 2020

DOl: https://doi.org/10.21203/rs.3.rs-29458/v1

License: (1) This work is licensed under a Creative Commons Attribution 4.0 International License.

Read Full License 


\section{Abstract}

Background: Malaria is one of the most important causes of morbidity and mortality in sub-Saharan Africa including Ethiopia. About $75 \%$ of the total area of the country is an area of malaria transmission and an estimated $68 \%$ of the Ethiopian population is at risk from malaria. Therfore, this study was aimed to evaluate local malaria incidence and associated risk factors in and around Anger Gute town, East Wollega Zone,Oromia Regional State, Western Ethiopia.

Methods: Health-facility based cross-sectional study was carried out from June to December 2018. 462 malaria suspected patients attending three health posts and one health center were included in the study. Data were collected using structured questionnaire and laboratory diagnosis of malaria. Data analysis was performed using SPSS version 20.0 for windows. Logistic regression was used to examine the effect of each independent variable on incidence of malaria. $P$ values of less or equal to 0.05 were considered significant.

Results : Of 462 malaria suspected cases, $122(26.4 \%)$ had Plasmodium infection which was confirmed by microscopy or RDT. $64.75 \%, 32 \%$ and $3.75 \%$ of malaria was caused by P. falciparum, P. vivax and mixed infections respectively. Malaria incidence in and around Anger Gute town from June to December 2018 was found to be $0.343 \%(122 / 35,585)$. No significant difference in incidence of malaria was found by sex and age categories of study participants $(P>0.05)$. Incidence of malaria was significantly lower in urban kebeles compared to rural kebeles (COR=0.359, $P=0.00)$. Incidence of malaria was significantly associated with presence of stagnant water nearby living house ( $A O D=186.3, P=0.000)$, utilization of bed net $(A O D=0.08, P=0.000)$, and IRS $(A O D=0.056, P=0.03)$. Six years malaria trend analysis at Anger Gute Health Center showed that number of confirmed malaria cases was significantly decreased in 2014 - 2018 as compared to 2013. Since 2014; numbers of confirmed malaria cases have been more or less constant in Anger Gute health center.

Conclusions: Incidence of malaria in and around Anger Gute town was 3.43 per 1000 population at risk of the disease during the study period and was lower than recent incidence of malaria reported from Ethiopia. Trend analysis of malaria from 2014 to 2018 indicated nearly unchanged numbers of malaria cases. This shows presence of low sustained malaria transmission. Integrated vector control efforts are needed to suppress transmission that lead to elimination of the disease in the study setting. Key words: Anger Gute, malaria, malaria incidence

\section{Background}

In 2011, the world health Assembly, Roll Back malaria partnership, set the objectives to reduce malaria case by $75 \%$ and malaria deaths to near zero from 200 levels by 2015 [1]. Progress reports there after showed globally, malaria case decreased from 227 million in 2000 to 198 million in 2013 [2]. The incidence was projected to fall by $35 \%$ globally and by $40 \%$ in the African region by 2015 . In Ethiopia, malaria is one of the leading causes of morbidity and mortality. It is estimated that about $75 \%$ of the total 
area of the country and $68 \%$ of the population were exposed to malarial infection [3]. The important infectious agents of malaria in the country are; Plasmodium falciparum and Plasmodium vivax, that account for $60 \%$ and $40 \%$ of malaria cases, respectively [4].Malaria is seasonal in most parts of Ethiopia and its transmission picks biannually from September to December (major transmission) and from April to May (minor transmission), coinciding with the major harvesting seasons [5].

In Ethiopia, regardless of implementation of control interventions for a couple of decades and achievements of a $50 \%$ reduction target of malaria of the millennium development goals [6], malaria still remains a major public health problem [7].The country is planning to eliminate malaria in the upcoming decades. The current core malaria control and elimination interventions are prompt treatment of cases using artemisinin-based combination therapy (ACT) and massive operational deployment of long-lasting insecticidal nets (LLINs) and indoor residual spray (IRS) [5].

In the derive to eliminate malaria, evidence about local and focal transmission of the disease as well as status of local community exposure to the frontline malaria intervention tools such as LLINs and IRS is needed for informed decisions and learn more about the effectiveness and efficacy of interventions in routine malaria control programs. To consolidate such evidence generation and informed decisions for malaria control and elimination goals, the Ethiopian National Malaria Control Program (NMCP) has established 25 Malaria Surveillance Sentinel Sites (MSSs) across the country [8].

The NMCP collaborates with various institutions from the health and education sectors such as the academia, research institutes and Non Governmental Organizations (NGOs) for evidence generation and evaluation of program implementation and research at each MSS. One of the 25 MSSs targeted for malaria research in collaboration with Wollega University and the NMCP, Ethiopian Public Health Research Institute (EPHI) and other stakeholders is Anger Gute MSS. Empirical evidence on malaria transmission incidence, prevalence and associated risk factors has been lacking and warrant basic and operational research at the MSS This study therefore, aims to provide evidence about focal malaria transmission incidence, associated risk factors and six years malaria trend analysis in the MSS particularly in and around Anger Gute town, East Wollega Zone, Oromia Regional State, Western Ethiopia.

\section{Methods}

\section{Study area and period}

The study was conducted in two malarious kebeles of Anger Gute town and the surrounding three kebeles from June to December 2018. Anger Gute area is found in Gida Ayana district in the East Wollega Zone of Oromia Regional State, western Ethiopia (Figure 1). The study area is located about $360 \mathrm{~km}$ west of Addis Ababa along the main road connecting Jimma to Bahir Dar via Nekemte and set in the Anger River Valley (upper Blue Nile Valley) in western Ethiopia. The population of this sub-district is 59,445.The altitude of the area is between $1200 \mathrm{~m}$ to $1500 \mathrm{~m}$ above sea level and on global positioning, the study area is located at latitude of $\mathrm{N}^{0} 33^{\prime} 57^{\prime \prime}$ and longitude of $\mathrm{E} 36^{0} 37^{\prime} 57$. The daily mean temperature is $28^{\circ} \mathrm{c}$ which is a 
conducive environment for mosquito population to breed. The area is affected by seasonal/unstable malaria transmission.

\section{Study design}

Health facility-based cross-sectional study was undertaken in purposefully selected two urban and three surrounding malarious kebeles. Selection of the study kebeles were based on presence of mosquito breeding drainages and wetlands such as rivers and swampy areas. In addition, a retrospective clinical study of six years malaria trend assessment (2013 to 2018) was conducted at Anger Gute health centre.

\section{Study population}

Malaria suspected patients at three health posts of the rural kebeles and one urban health center were included in the study. Five Kebeles (Anger Gute 01, 02 kebele, Warabo, Tulu Lencha and Dalasa Makanisa) which were purposefully selected from surrounding malarious kebeles of Anger Gute town were included in the study.

\section{Sampling method}

Convenient sampling techniques was used to include all malaria suspected patients (462) who came to Anger Gute health center, Warabo, Tulu Lencha and D alasa Makanisa health posts.

\section{Data collection methods}

\section{Malaria parasite microscopy}

Data were collected using malaria parasite microscopy in health center and rapid diagnostic tests (RDT) in health posts. Once patients were suspected of malaria mainly based on fever (body temperature $\geq 37.5$ ${ }^{\circ} \mathrm{C}$ and/or history of fever in the last $48 \mathrm{~h}$ ), a finger prick blood samples were collected for RDTs and microscopic slide examination. Microscopic slides were prepared according to WHO guidelines [9], and the slides were read by two expert microscopists. Discordant slides were read for a third time by a senior microscopist.

\section{Structured questionnaire survey}

For health-facility based cross-sectional survey study, a structured questionnaire addressing sociodemographics and risk factors or preventive measures of malaria of patients attending three health posts and one health center were used. The survey questionnaire was based on the malaria indicator 
survey household questionnaires, which were filled by the participants. The questionnaire was administered to 462 volunteers by trained interviewers considering the schedule of the participants.

\section{Retrospective health-facility data}

Secondary data were retrieved on malaria in the past 6-year (2013-2018) from the health service laboratory unit registry to compute the trend of malaria in the community.

\section{Data entry and analysis}

Data entry and analysis were performed using SPSS 20.0 for windows software. Logistic regression analysis was used to determine presence of association between incidence of malaria and associated risk factors. $P$ values of less or equal to 0.05 were considered significant.

\section{Results}

\section{Socio-demographic characteristic of the study participants}

A total of 462 malaria suspected patients from three health posts and one health center were included in the study of which, $52.2 \%$ were female and $47.2 \%$ were male. Residentially, $73.2 \%$ were rural while $26.8 \%$ were urban. Regarding educational status $39.6 \%$ and $43.1 \%$ of malaria suspected individuals were illiterate and had primary school educational status respectively (Table 1). 
Table 1

Socio demographic characteristics of malaria suspected individuals in and around Anger Gute town $(n=462)$

\begin{tabular}{|lll|}
\hline Variables & Frequency & Percent \\
\hline Sex Male & 218 & 47.2 \\
\hline Female & 244 & 52.8 \\
\hline Age in years & & \\
\hline$<5$ & 17 & 3.7 \\
\hline $5-14$ & 112 & 24.2 \\
\hline $15-30$ & 134 & 29.0 \\
\hline $30-49$ & 190 & 41.1 \\
\hline$>49$ & 9 & 1.9 \\
\hline Educational status & & \\
\hline Illiterate & 183 & 39.6 \\
\hline Primary & 199 & 43.1 \\
\hline Secondary & 51 & 11.0 \\
\hline Tertiary & 4 & 0.9 \\
\hline Under age & 25 & 5.4 \\
\hline Residence & & \\
\hline Urban & 124 & 26.8 \\
\hline Rural & 338 & 73.2 \\
\hline
\end{tabular}

\section{Incidence Of Malaria}

From a total of 462 malaria suspected individuals, 122 (26.4\%) were positive for plasmodium infection, while $340(74 \%)$ were negative.

Incidence of malaria in and around Anger Gute town from June to December, 2018 was 3.43 per 1000 population at risk of the disease during the study period $(122 / 35,585=0.00343=0.343 \%)$.

Among positive cases, $64.75 \%$ (79/122), 32\% (39/122) and 3.75\% (4/122) of malaria was caused by $P$. falciparum, $P$. vivax and mixed infections respectively (Fig. 2). 


\section{Incidence Of Malaria And Socio-demographic Characteristics}

No significant difference in incidence of malaria were found by sex and age categories of malaria suspected individuals $(P>0.05)$. Incidence of malaria was significantly lower in the urban kebeles compared to the rural ones $(\mathrm{COR}=0.359, \mathrm{P}=0.00)($ Table 2$)$.

Table 2

Association between socio-demographic characteristics and incidence of malaria in and around Anger Gute town $(n=462)$

\begin{tabular}{|lllll|}
\hline Variable & \multicolumn{2}{l}{$\begin{array}{l}\text { Plasmodium } \\
\text { infection }\end{array}$} & COR & $\begin{array}{l}\text { p- } \\
\text { value }\end{array}$ \\
\hline Sex Male & 61 & 157 & 1.167 & 0.468 \\
\hline Female & 61 & 183 & 1 & \\
\hline Age & & & & \\
\hline$<5$ & 3 & 14 & 1.714 & 0.664 \\
\hline $5-14$ & 22 & 90 & 1.956 & 0.537 \\
\hline $15-30$ & 44 & 90 & 3.9 & 0.205 \\
\hline $30-49$ & 52 & 138 & 3 & 0.304 \\
\hline$>49$ & 1 & 8 & 1 & \\
\hline Residence & & & & \\
\hline Urban & 14 & 110 & 0.359 & 0.00 \\
\hline Rural & 108 & 230 & 1 & \\
\hline
\end{tabular}

Incidence of malaria in relation with risk factors and preventive measures

Outdoor sleeping behavior, sleeping hand and face covered and living house roof type were not associated with incidence of malaria $(P>0.05)$. However, incidence of malaria was significantly associated with presence of stagnant water nearby living house, utilization of bed net and IRS $(P<0.05)$ (Table 3). 
Table 3

Incidence of malaria in relation with risk factors or preventive measures of malaria in and around Anger Gute town $(n=462)$

\begin{tabular}{|c|c|c|c|c|c|c|}
\hline \multirow[t]{2}{*}{ Variable } & \multicolumn{2}{|c|}{ Plasmodium infection } & \multirow[t]{2}{*}{ COD } & \multirow[t]{2}{*}{ p-value } & \multirow[t]{2}{*}{ AOD } & \multirow[t]{2}{*}{ p-value } \\
\hline & Yes & No & & & & \\
\hline \multicolumn{7}{|c|}{ Stagnant water near living house } \\
\hline Yes & 92 & 11 & 91.72 & 0.000 & 186.3 & 0.00 \\
\hline No & 30 & 329 & 1 & & 1 & \\
\hline \multicolumn{7}{|l|}{ Sleep out door } \\
\hline Yes & 24 & 98 & 2.53 & 0.002 & 1.68 & 0.346 \\
\hline No & 30 & 310 & 1 & & 1 & \\
\hline \multicolumn{7}{|l|}{ Sleeping } \\
\hline Hand \& face covered & 36 & 86 & 0.363 & 0.00 & 2.05 & 0.11 \\
\hline Hand and face not covered & 182 & 158 & 1 & & 1 & \\
\hline \multicolumn{7}{|l|}{ Roof type } \\
\hline Corrugate & 99 & 292 & 0.71 & 0.215 & 0.425 & 0.35 \\
\hline Straw & 23 & 48 & 1 & & 1 & \\
\hline \multicolumn{7}{|l|}{ Wall of house } \\
\hline Cracked & 33 & 52 & 1.991 & 0.007 & 1.178 & 0.874 \\
\hline Hole & 2 & 15 & 0.42 & 0.253 & 0.529 & 0.557 \\
\hline No crack or hole & 87 & 273 & 1 & & 1 & \\
\hline \multicolumn{7}{|l|}{ Bed net presence } \\
\hline Yes & 26 & 264 & 0.078 & 0.000 & 1.075 & 0.905 \\
\hline No & 96 & 76 & 1 & & 1 & \\
\hline \multicolumn{7}{|l|}{ Bed net utilization } \\
\hline Yes & 3 & 249 & 0.009 & 0.00 & 0.08 & 0.00 \\
\hline No & 119 & 91 & 1 & & 1 & \\
\hline \multicolumn{7}{|l|}{ IRS } \\
\hline Yes & 2 & 178 & 0.015 & 0.00 & 0.056 & 0.03 \\
\hline No & 120 & 162 & 1 & & 1 & \\
\hline
\end{tabular}




\section{Retrospective Trend Of Malaria}

Number of confirmed malaria cases was significantly decreased from 2014-2018 as compared to 2013. Since 2014; number of confirmed Plasmodium has been more or less constant among in Anger Gute health center (Fig. 3).

\section{Discussions}

In the present study, the investigators tried to evaluate local malaria incidence and associated risk factors in and around Anger Gute town, East Wollega Zone,Oromia Regional State, Western Ethiopia.Results showed that the overall incidence of malaria in and around Anger Gute town was 3.43 per 1000 population/seven months from June to December 2018 at risk of the disease. This incidence rate was lower than global incidence rate of malaria reported in 2017 which was 59 cases per 1000 population at risk [10].This finding was also lower than recent incidence of the disease reported from Ethiopia which was 29.0 cases per 1000 population/year [11]. Reduction in incidence of malaria in and around Anger Gute malaria endemic areas is evident toward malaria elimination.

Results also underscore that incidence of malaria was higher in rural areas than urban. This is in agreement with study conducted by [12] and could be expected because rural areas are considered to be at higher risk of malaria compared to urban areas because of less improved housing, lower socioeconomic status and large number of breeding sites for malaria vectors in rural than urban areas. It was also found that the occurrence of malaria in and around Anger Gute town was 186 times more among study participants who had stagnant water nearby their living house as compared to those who did not have proximity to such mosquito breeding sites. This is also in line with findings reported by [13] and showed importance of source reduction in control of malaria through environmental modification, draining and filling.

Use of mosquito net as protective measure against mosquito bites in the last 12 months was high in the study setting. This result coincides with a study conducted by [14] in Arba Minch Southern Ethiopia in which, use of mosquito net as malaria preventive measure was high while, other preventive measures such as environmental modification and draining and filling was low among residents. This study has shown that core malaria preventive measures such as insecticide treated bed net utilization and IRS have protective role for occurrence of malaria.

Six years trend analysis of confirmed malaria cases at Anger Gute health canter indicated a decrease in number of cases in the past five years as compared to 2013 which is in line with research conducted by [11]. However, number of malaria cases were nearly constant in 2014 to 2018, indicating low sustained malaria transmission in the study area. Intervention tools available currently can most likely reduce transmission and gains made during recent years in reducing number of malaria cases as compared to 2013. As reported by [15] this findings also shows that lowering number of cases may comparatively be 
easy, but complete elimination of the disease may not be so easy indicating further efforts are needed to suppress transmission that lead to elimination of the disease.

\section{Conclusion}

Incidence of malaria in and around Anger Gute town was 3.43 per 1000 population at risk of the disease during the seven months of study. This incidence of the disease was lower than recent incidence of malaria reported from Ethiopia. Trend analysis of malaria from 2014 to 2018 indicated nearly unchanged numbers of malaria cases and shows presence of low sustained malaria transmission. Integrated vector control efforts are needed to suppress transmission that lead to elimination of the disease.

\section{Abbreviations}

ACT

Artemisinin-based Combination Therapy; AOR:Adjusted Odds Ratio;COR:Crude Odds Ratio; EPHI:Ethiopian Public Health Research Institute; FMoH:Federal Ministry of Health;IRS:Indoor Residual Spray;LLINs:long-lasting Insecticidal Nets;MOP:Malaria Operational Plan;MSSs Malaria Surveillance Sentinel Sites; NGO:Non Governmental Organizations; NMCP:National Malaria Control Program; RDT:Rapid Diagnostic Test;WHO:World Health Organization;WMR:World Malaria Report.

\section{Declarations}

\section{Acknowledgments}

The authors are grateful to the study participants. Our special thanks also go to Anger Gute health centre administrative staff in general and laboratory technologists in particular for their essential support during a site survey. Finally, we are thankful the funder, office of vice president for research community engagement and technology transfer, Wollega University.

\section{Author contributions}

OK and MD conceptualized the idea and drafted the initial proposal. OK, MD and GT was finalized the study proposal. OK, MD and GT were leading the development of the data collection tools. MD and GT contributed to data processing and analysis. MD drafted the manuscript. All authors read and approved the final manuscript.

\section{Funding}

This study was financially supported by the office of vice president for research community engagement and technology transfer, Wollega University. The funder has no role in the design of the study, data collection, analysis, interpretation and in writing the manuscript.

\section{Availability of data and materials}


The data set generated from patients' clinical records is not publicly available to protect patient confidentiality. Unidentifiable data can be obtained from the corresponding author upon reasonable request.

\section{Ethics approval and consent to participate}

Ethical approval was obtained from Wollega University Research Ethics Review Committee. The informed consent obtained was verbally in their local language. For children under the age of 18 ; assent was obtained from their parents or guardians.

\section{Consent to publish}

Not applicable

\section{Competing interests}

The authors declare that they have no competing interests regarding the publication of this manuscript.

\section{Author details}

${ }^{1 *} \mathrm{PhD}$. in Biomedical Sciences, currently working as an Assistant professor under college of natural and computational sciences, Department of Biology, Wollega University.

${ }^{1} \mathrm{PhD}$. in Medical Entomology, currently working as an Assistant professor under college of natural and computational sciences, Department of Biology,Wollega University.

${ }^{2} \mathrm{MSc}$. In Medical Laboratory Science, Assistant professor under the Institute of Health Sciences, Department of Medical Laboratory Sciences, Wollega University

\section{References}

1. World Health Organization. World malaria report 2012. 2012. Geneva: World Health Organization. 2014:1-276.

2. World Health Organization. World malaria report 2014. Geneva: WHO Press.

3. World Health Organization. Malaria rapid diagnostic test performance. Geneva: World Health Organization; 2007.

4. World Health Organization. World malaria report 2013. Geneva: WHO Press.

5. Federal Democratic Republic of Ethiopia Ministry of Health. National Five Year Strategic Plan for Malaria Prevention and Control in Ethiopia: 2006-2010.

6. Deribew A, Dejene T, Kebede B, Tessema GA, Melaku YA, Misganaw A, Gebre T, Hailu A, Biadgilign S, Amberbir A, Yirsaw BD. Incidence, prevalence and mortality rates of malaria in Ethiopia from 1990 to 2015: analysis of the global burden of diseases 2015. Malar J. 2017 Dec;16(1):271. 
7. World Health Organization. A framework for malaria elimination. World Health Organization; 2017.

8. Malaria Operational Plan FY. (2019). https:// malaria-operational-plans\%2Ffy19\%2Ffy-2019ethiopia\&btnG.

9. World Health Organization. Basic malaria microscopy. World Health Organization; 1991.

10. World Malaria Report. (2019). Regional and global trends in burden of malaria cases and deaths. https://www.who.int/news-room/feature-stories/detail/world-malaria-report-2019.

11. Infectious diseases of poverty Taffese HS, Hemming-Schroeder E, Koepfli C, Tesfaye G, Lee MC, Kazura J, Yan GY, Zhou GF. Malaria epidemiology and interventions in Ethiopia from 2001 to 2016. Infectious diseases of poverty. 2018 Dec; 7(1):1-9.

12. Gómez KM, Caicedo MA, Gaitán A, Herrera-Varela M, Arce MI, Vallejo AF, Padilla J, Chaparro P, Pacheco MA, Escalante AA, Arevalo-Herrera M. Characterizing the malaria rural-to-urban transmission interface: The importance of reactive case detection. PLoS neglected tropical diseases. 2017 Jul 17; 11(7):e0005780.

13. Tusting LS, Thwing J, Sinclair D, Fillinger U, Gimnig J, Bonner KE, Bottomley C, Lindsay SW. Mosquito larval source management for controlling malaria. Cochrane Database of Systematic Reviews. 2013(8).

14. Astatkie A. Knowledge and practice of malaria prevention methods among residents of Arba Minch Town and Arba Minch Zuria District, Southern Ethiopia. Ethiopian journal of health sciences. 2010; 20(3).

15. Dhiman S. Are malaria elimination efforts on right track? An analysis of gains achieved and challenges ahead. Infectious diseases of poverty. 2019 Dec;8(1):14. 